\title{
Final Report (01-ERD-051) Dynamic InSAR: Imaging Seismic Waves Remotely from Space
}

P. Vincent, A. Rodgers, D. Dodge, J. Zucca, C. Schultz, B. Walter, M. Portnoff

February 7, 2003

U.S. Department of Energy

Lawrence

Livermore

National

Laboratory

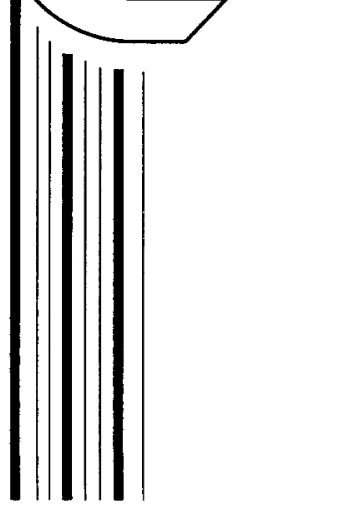




\section{DISCLAIMER}

This document was prepared as an account of work sponsored by an agency of the United States Government. Neither the United States Government nor the University of California nor any of their employees, makes any warranty, express or implied, or assumes any legal liability or responsibility for the accuracy, completeness, or usefulness of any information, apparatus, product, or process disclosed, or represents that its use would not infringe privately owned rights. Reference herein to any specific commercial product, process, or service by trade name, trademark, manufacturer, or otherwise, does not necessarily constitute or imply its endorsement, recommendation, or favoring by the United States Government or the University of California. The views and opinions of authors expressed herein do not necessarily state or reflect those of the United States Government or the University of California, and shall not be used for advertising or product endorsement purposes.

This work was performed under the auspices of the U.S. Department of Energy by the University of California, Lawrence Livermore National Laboratory under Contract No. W-7405-Eng-48.

This report has been reproduced directly from the best available copy.

Available electronically at http://www.doc.gov/bridge

Available for a processing fee to U.S. Department of Energy

And its contractors in paper from

U.S. Department of Energy

Office of Scientific and Technical Information

P.O. Box 62

Oak Ridge, TN 37831-0062

Telephone: (865) 576-8401

Facsimile: (865) 576-5728

E-mail: reports@adonis.osti.gov

Available for the sale to the public from

U.S. Department of Commerce

National Technical Information Service

5285 Port Royal Road

Springfield, VA 22161

Telephone: (800) 553-6847

Facsimile: (703) 605-6900

E-mail: orders@ntis.fedworld.gov

Online ordering: http://www.ntis.gov/ordering.htm

OR

Lawrence Livermore National Laboratory

Technical Information Department's Digital Library

http://www.llnl.gov/tid/Library.html 


\section{Introduction}

This final report summarizes the accomplishments of the originally-planned 2-year project that was cut short to 1 year plus 2 months due to a funding priority change that occurred in the aftermath of the September $11^{\text {th }}$ tragedy. The LDRD-ER project "Dynamic InSAR: Imaging Seismic Waves from Space" (01-ERD-051) began in October, (FY01) and ended in December (FY02). Consequently, most of the results and conclusions for this project are represented in the FY01 Annual Report. Nonetheless, additional conclusions and insights regarding the progress of this work are included in this report. In should be noted that this work was restarted and received additional funding under the NA-22 DOE Nonproliferation Program in FY03.

\section{Purpose and Relevance of Project}

The purpose of this LDRD project was to determine the feasibility of using InSAR (interferometric synthetic aperture radar) to image seismic waves remotely from space. If shown to be feasible, the longterm goal of this project would be to influence future SAR satellite missions and airborne SAR platforms to include a this new capability.

Most of what we currently understand about the earth-its internal structure and dynamic interior, as well as our understanding of earthquakes and our ability to predict volcanic eruptions, has come from seismology. Seismology also plays a dominant role in monitoring global man-made seismic activity, such as underground mining and nuclear test activity. Seismology, however, is an inherently "blind" methodology, whereby the seismic waves recorded at seismometers are never actually "seen" directly, but are recorded by the effect they have on seismic instruments as the seismic waves pass by. In addition, the relatively sparse spatial sampling on the earth's land surface and nearly complete lack of spatial sampling over the oceans, further limits the information available. If, however, seismic waves could be imaged remotely from space and/or from an aircraft, a spatially continuous "picture" of seismic waves would be available that could greatly increase our understanding of seismic wave propagation, dispersion, and boundary interaction (reflection and refraction). Applications of such a capability relevant to NAI missions include bomb damage assessment/earth-penetrator coupling, underground facility detection, and regional calibration of seismic location correction surfaces for underground nuclear explosion monitoring. Other applications could include earthquake rupture physics, volcano harmonic tremor source characterization, and an open ocean tsunami tracking and early warning system.

\section{InSAR Method}

Interferometric synthetic aperture radar (InSAR) has become the standard geodetic tool for mapping surface displacements from a variety of sources such as faults, glaciers, fluid reservoirs (oil, gas, geothermal, volcanic) as well as from soil compaction from aquifer discharge and recharge. The quasicontinuous maps of surface displacement provide the added constraints needed to produce more accurate models of these sources.

Figure 1 shows the basic scanning geometry of a space-borne SAR where a radar backscatter map is formed by scanning the Earth's surface in a side-looking fashion. As the satellite sensor moves along its orbital path with velocity Vs, it transmits microwave pulses and echoes are received from each pulse at the same antenna. The region on the ground illuminated by a single pulse is referred to as the antenna footprint and the entire imaged strip is called the swath. SAR data are divided into $100 \mathrm{~km}$ by $100 \mathrm{~km}$ frames and are processed one-at-a-time. Once processed, individual frames can be combined interferometrically with those from another (repeat) orbit and the resulting phase difference will be proportional to the change in range to the satellite from each ground pixel $(25 \mathrm{~m} \times 25 \mathrm{~m})$ that occurred between imaging times (after topographic phase is removed). From this information, a geo-referenced surface deformation map can be produced with sub-centimeter sensitivity and 30 meter resolution. It is these deformation maps, or interferograms, that allow for the construction of more accurate source models by constraining the surface deformation these models are allowed to predict. 


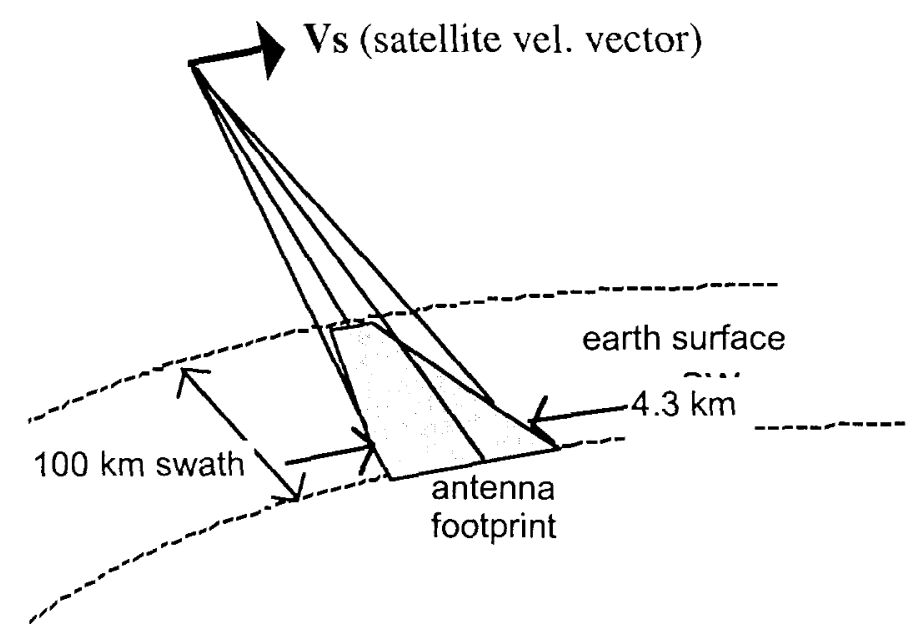

Figure 1. Imaging geometry of a space-borne SAR (swath width and antenna footprint are given for the commercial ERS-1 SAR satellite; Not-to-scale).

\section{Dynamic InSAR Method}

While static InSAR measures the total accumulated surface displacement field between repeat-pass orbit imaging times, dynamic InSAR measures the dynamic displacements that occur in real time during one of the two individual SAR image collections. Alternatively, two antennas can be mounted on a single SAR platform so that only one pass is needed to capture topography changes dynamically (e.g., water waves). For example, a dynamic InSAR system has measured the motion (velocity) of water waves on the ocean surface just off shore from Point Loma, CA using two SAR antennas, spaced 20 meters apart along the underside of the fuselage of NASA's DC-9 AirSAR aircraft [Goldstein, et al, in Nature, 1989]. Seismic waves, however, move much faster, and with much smaller vertical displacements that water waves. This renders the configuration used by JPL scientists to image water waves (i.e., with two SAR antennas separated by 20 meters) useless because the interferometric phase would change much too rapidly to maintain coherence and avoid phase cycle ambiguities. Given this limitation, our approach was to try to capture an earthquake-generated Rayleigh wave in a single satellite pass.

The first step toward achieving this goal was to use commercially available archived SAR satellite data to try to produce an InSAR image of a seismic wave from a past seismic source such as an earthquake or explosion. In principle, this could be done by interfering a SAR data collection that captures a seismic wave in one orbit pass with another SAR image of the same ground region from another orbit-the phase difference between these two SAR images should result in only the seismic wave perturbation being present. The challenge was to find an archived SAR image that captured a $3-8 \mathrm{~km} / \mathrm{sec}$ moving seismic wave in its image frame. To do this the precise space-time location of a candidate seismic wave is accurately predicted as a function of distance from its source, and an intersection was is found with the satellite imaging swath where the intersection must occur before the seismic waves decays below InSAR detection thresholds. We developed the algorithms to do this search and our intersection accuracy out 180 degrees from the source was better than 10 seconds (as verified by seismic station recordings closest to our intersection points). We found SAR data for two such candidate intersections, but the predicted displacements were only one millimeter, and while on land, the area contained either vegetation or snow and consequently the data was deemed not worth purchasing.

In the second half of the (shortened) project period, we began working on a controlled, triggered seismic wave SAR collection experiment. To determine the expected surfacê displacements from an explosive source, we collected seismic data from large $40 \mathrm{k}$ lbs rocket motor detonations conducted at the Utah Test and Training Range near Salt Lake (see Figure in LDRDFY00 Annual Report). Theses data, along with our simulations using LLNL's E3D seismic simulation code, was used to calibrate a future SAR collection experiment. At this point the project ended prematurely as explained above. While we did not have enough time to fulfill our object, we did make significant progress and have continued this work under alternative funding.

\section{Future Work}

This work is continuing under different funding as described above. 